\title{
Lycopene Rich Drink: Consumers Acceptance and Purchase Intention in Malaysia
}

\author{
Rawaida Rusli1,a; Siti ‘Aisyah Baharudin',b*; Nur Fazliana Md.Noh ${ }^{3, c}$; Mohamad \\ Nazim Anvarali4,d; Hadijah Hassan ${ }^{5, \mathrm{e}}$ \\ 1rawaida@mardi.gov.my; ${ }^{2}$ sab16@usm.my; 3 fazliana@mardi.gov.my; \\ nazim@mardi.gov.my; 5 hadijah@mardi.gov.my
}

a, c, d, e Malaysia Agricultural Research Development Institute; bUniversiti Sains Malaysia

*corresponding authors

Article history

Received : 10-08-2021

Revised : 18-09-2021

Accepted : 21-09-2021

Keywords

Consumers Acceptance

Functional Beverages

Lycopene Rich Drink

MARDI

Purchase Intention
This study had been carried out to assess the level of consumers' acceptance and purchase intention towards new functional beverages developed by the Malaysia Agricultural Research Development Institute (MARDI). The Lycopene Rich Drink (LRD) had been assessed towards 400 respondents in 4 Zone in Malaysia which is Northern, Southern, Western, and Eastern using stratified sampling. The results revealed that the consumers had well accepted the LRD based on the highest mean score acceptance (mean=4.16) compared to the commercial (mean=3.15) beverages in the market. Taste and color are the most preferred attributes that influenced the purchase intention. The logistic regression analysis had predicted almost $95 \%$ of the respondents' intent to purchase. Marital status and number of households are the sociodemographic factors that show a significant relationship based on the Chi-Square analysis. The findings of this study are beneficial for the beverages industry players towards exploiting the opportunity of health additional benefit offered.

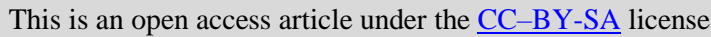

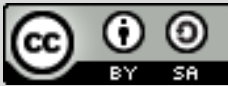

\section{Introduction}

Rich Drink is one of the categories in the functional beverages. Functional beverage had gained attention nowadays for the additional benefit offered (Sahar et al., 2019). The term 'functional food' emerged from Japan in 1993 when Japan started to explores the boundary between food and medicine (Henry, 2010; Siro et al., 2008; Hardy, 2000; Kwak \& Jukes, 2001 and Stanton et al., 2005). Functional food had a great potential to be incorporated with desirable nutritional ingredients and bioactive compounds such as vitamins, minerals, antioxidants, fatty acids, fiber, prebiotics, and probiotics (Zaidel et al., 2021). Chang, Ma, \& Chen (2020) define 'functional beverages' contain additives to reduce blood lipids, reduce fat absorption, aid digestion and many other body functions. Functional beverages are emerging markets due to the new functional beverages added and 
health-related benefits combining with the strategies such as digestion, energy, aging, satiety, cognitive ability, hydration, weight management, and fatigue (Sahar et al., 2019). In addition, the global functional beverage market is projected to grow at $6.96 \%$ of Cumulative Average Growth Rate (CAGR) during the forecast period (2021-2016) with the market size valued at $\$ 43.4$ billion by 2023 . Asia-Pacific recorded the emerging growth due to the high incidence of non-communicable diseases (NCDs) and changing lifestyles (Mordor Intelligence, 2021). The functional beverages can be split into three types which are (i) dairy-based beverages including probiotics and minerals-3 enriched drinks, (ii) vegetable and fruit beverages, and (iii) sports and energy drinks (Corbo et al., 2014).

Lycopene Rch Drink (LRD) is originated from watermelon fruits. Watermelon is in third rank highest of fruit production (155, 210 metric tonnes) after pineapple and banana (Ministry of Agriculture and Food Industry, 2020). These tropical fruits had been given attention in National Agro-Food Policy (NAFP) throughout 2011-2020 to elevate high-value downstream research efforts through research and development (R\&D) activities in Malaysian Agricultural Research and Development Institute (MARDI). In addition to that, NAFP (2011-2020) also focusing on the efficiency of the Malaysian agro-food industry. Therefore, MARDI had developed LRD which contain part of the functional ingredients that offered vast health benefits such as higher Vitamin A and antioxidants as well as potential in reducing the risk of NCDs (Maoto, Beswa, \& Jideani, 2019). The LRD is packaged in $250 \mathrm{ml}$ glass bottle can be stored at room temperature for 6 months and delicious to enjoy in cold temperatures. A bottle of this LRD supplies no less than $10 \mathrm{mg}$ of natural lycopene. This drink was also observed to improve kidney function where the urea content in the blood was low (Ried \& Fakler, 2011).

There are many studies done to assess consumer acceptance of functional beverages. This is important to get input related to consumer acceptance and consumer willingness to buy due to various factors such as taste, healthy features, and price. For example, a study by Sabbe et al. (2009) showed that sensory qualities such as texture, flavor, aroma and visual are the main factors that determine the acceptance and readiness to obtain the product. It is supported by Luckow \& Delahunty (2004) which examines the comparison of consumer acceptance of natural blackcurrant juice and commercially processed blackcurrant juice. The indicators used are appearance, aroma, texture, and flavor. The results show that consumers have chosen natural juice as the most preferred juice product. It is directly related to gender and age. Whereas, a study by Skąpska, et al. (2020) showed the main motivation for buying functional drinks was their sensory acceptance in terms of taste, smell, color, and overall quality, even when consumers were informed of their potential 
health benefits.

Therefore, this study was carried out to assess the level of consumers' acceptance and purchase intention towards the new product's development. In ensuring high success for a new food product in the market, consumers' voice plays a vital role (Dijksterhuisn 2016; Grunert et al., 2010; Kemp, 2013; Van Kleef and Van Trijp 2007) and has become widely accepted in today's innovation practices (Moskowitz and Hartmann 2008). In addition, this study is useful for the consumers' perspective and the opportunities for the Malaysian beverage industry players as well as effective marketing strategy towards new food product development.

\section{Method}

\section{Data Collection}

This study involved the collection of primary data on 400 respondents in four-zone in Malaysia (Northern, Southern, Western, and Eastern) using stratified random sampling. Stratified random sampling is suitable for the strata randomize selection by zone (Darusalam \& Hussin, 2018). Data were obtained through face-to-face interviews using structured questionnaires and a $100 \%$ response rate recorded was thus anticipated in the survey. The respondents need to assess the LRD based on the product attributes such as taste and overall product acceptance (Rosniyana 2007), color (Jessica, 2008), aroma (Piqueras-Fiszman \& Spence, 2015), viscosity and fiber (Sahar et al., 2019). The respondents give the rank based on the 5 Likert Scale (1=strongly disagree, $2=$ disagree, $3=$ uncertain, $4=$ agree, $5=$ strongly disagree) based on the suggestion from TschannenMoran \& Gareis (2004). Later the mean score was interpreted as in Table 1.

Table 1. Mean Value for 5 Likert Scale

\begin{tabular}{cc}
\hline Mean Value & Interpretation \\
\hline $1.00-1.80$ & Very low \\
$1.81-2.60$ & Lower \\
$2.61-3.40$ & Average \\
$3.41-4.20$ & High \\
$4.21-5.00$ & Higher \\
\hline
\end{tabular}

Source: Tschannen-Moran \& Gareis (2004)

\section{Data Analysis}

All of the data collected were analyzed using IBM-SPSS Version 25. Descriptive analysis was performed for the profile of respondents' background, consumers' overall product acceptance, and product attributes. Later, Pearson Chi-square analysis was conducted to investigate any significant relationship between the consumers' overall product acceptance with the demographic factors. For the respondents' purchase intention towards attributes of LRD, a logistic regression analysis had been carried out. This statistical test is similar to 
regression but different in scale as it involved binary scale which is $(1=\mathrm{Yes})$ or $(0=\mathrm{No})$ (Chua, 2014). This study applied the logistic regression such as below:

$$
\begin{aligned}
& Y_{\text {lycopene functional beverage }}=\chi 0+\chi 1 \text { (Taste) }+\chi 2 \text { (Color) }+\chi^{3} \text { (Viscosity) }+ \\
& \chi 4 \text { (Aroma) }+\chi 5 \text { (Fiber) }
\end{aligned}
$$

Table 2. Magnitude effects of odds ratio

\begin{tabular}{ccc}
\hline The value of the odds ratio & Magnitude effect & Effect size \\
\hline$<1.0$ & Lower the opportunity & Small \\
$1.1-3.0$ & Increase the opportunity & Small \\
$3.1-5.0$ & Increase the opportunity & Moderate \\
$>5.0$ & Increase the opportunity & High \\
\hline
\end{tabular}

Source: Chua (2014)

The logistics regression revealed the respondents' purchase intention based on the LRD attributes either taste, color, aroma, viscosity, or fiber-based on the odd-ratio estimates. The odd ratio reveals the size of the independent variables on the dependent variables as shown in Table 2 (Chua 2014). Besides, the results also show the correct rate of, percentage of respondents being purchased bromelain functional beverages.

\section{Results and Discussions}

Table 3. Respondents Profile

\begin{tabular}{llc}
\hline \multicolumn{1}{c}{ Profile } & & Percentage (\%) \\
\hline Age (years) & 20 and below & 8 \\
& $21-30$ & 29 \\
& $31-40$ & 31 \\
Gender & $41-50$ & 22 \\
& Above 50 & 3 \\
Ethnicity & Male & 41 \\
& Female & 59 \\
& Malay & 87 \\
Education & Chinese & 10 \\
& Indian & 3 \\
Others & 1 \\
Income group & University/College & 54 \\
(RM/Month) & Secondary school & 44 \\
& Primary school & 2 \\
& Others & 1 \\
& $<$ RM2,500 & 42 \\
& RM2,501-RM4,850 & 34 \\
& RM4,851-RM7,100 & 11 \\
& RM 7,101-RM 10,970 & 8 \\
& RM10,971 - RM15,040 & 5 \\
& $>$ RM15,041 & 1 \\
\hline
\end{tabular}

Table 3 summarizes the respondents' profile of the study. The majority of the respondents' in a range age of 31 to 40 years old. More than half of the respondents were female (59\%) and ethnic Malay represented the largest ethnic group participate in this study. The majority of the respondents obtained education from a university or college 
(59\%). The income group of below RM 2,500 per month is the highest in this study.

\section{Consumers Acceptance towards Lycopene Rich Drink}

According to Figure 3, respondents have been asked to evaluate the acceptance towards LRD attributes such as taste, color, viscosity, aroma, fiber and overall acceptance. Respondents stated that LRD are more acceptable (mean=4.16) compared to commercial beverages (mean=3.15). Commercial beverages are the lycopene drinks that are available in the market. It has been chosen as a benchmark for the new product developed to be evaluated.

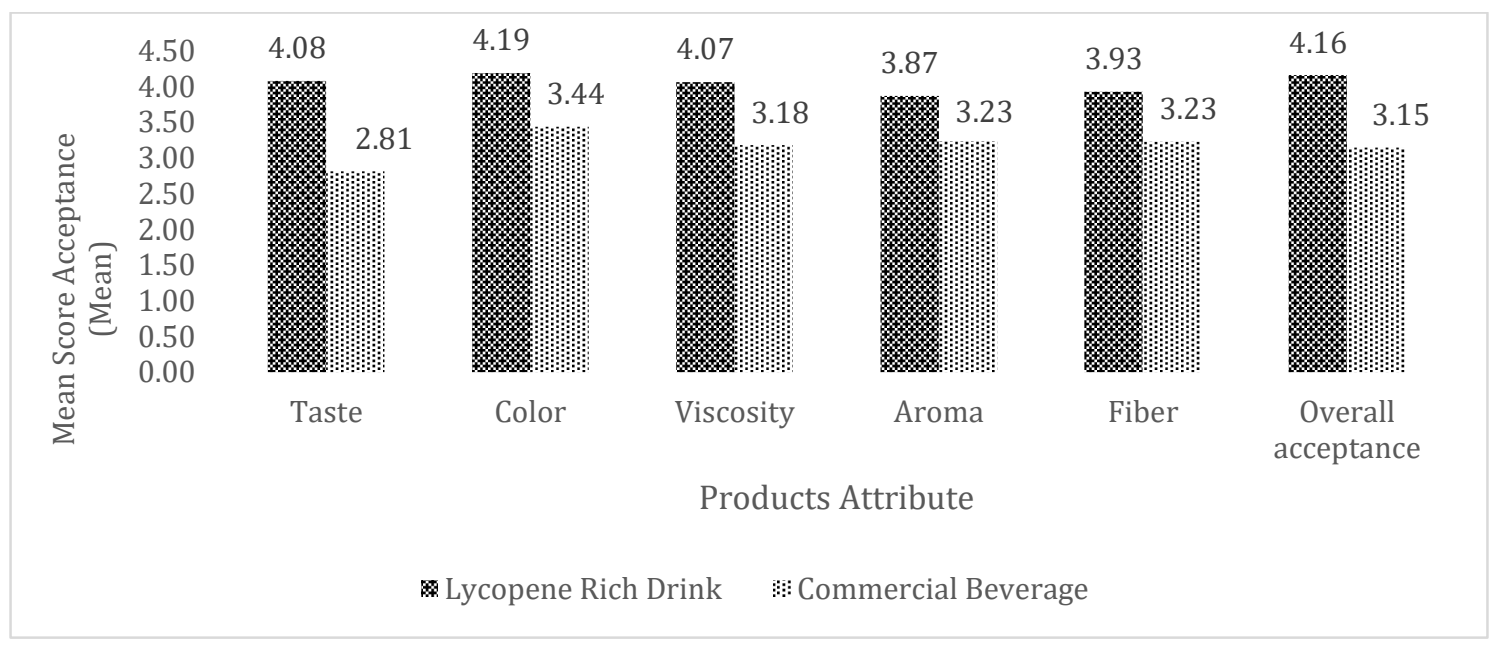

Figure 1. Mean score acceptance of Lycopene Rich Drink and commercial beverage

Based on the mean value interpretation from Tschannen-Moran \& Gareis (2004) as in Table 1, it revealed that the acceptability of LRD is high and the commercial beverage is in average value. In other words, respondents can accept the product well. According PF Guiné, Ramalhosa, \& Valente (2016), acceptance of the product especially new product development is very crucial to minimize the risks of failure through sensory analysis and market studies. Meanwhile, color, taste, and viscosity are the top three highest for product attributes selected by respondents. Marital status $\left(X^{2}=15.830, \mathrm{df}=8, p<0.005\right)$ and number of households $\left(X^{2}=56.052, \mathrm{df}=4, p<0.005\right)$ are the demographic factors that show a statistically significant relationship with consumers' overall product acceptance based on Chi-Square analysis. These findings suggest that these demographic factors are critical factors to be considered in marketing for the LRD.

\section{Consumers Purchase Intention towards Lycopene Rich Drink}

In determining whether the respondents would purchase based on the attributes product, binary logistic regression analysis had been carried out. It investigates any independents variables that contribute to the respondents' purchase intention. Table 4 summarizes the results of the binary logistics regression analysis. 
Table 4. Results of binary logistics regression analysis

\begin{tabular}{lccccccc}
\hline Attributes & B & S.E & Wald & df & Sig & Exp (B) & Nagelkerke(R ${ }^{2}$ ) \\
\hline Taste & $1.933^{*}$ & .569 & 11.559 & 1 & .001 & 6.914 & 0.212 \\
Colour & $1.290^{* *}$ & .612 & 4.443 & 1 & .035 & 3.631 & \\
Aroma & .230 & .559 & .169 & 1 & .681 & 1.258 & \\
Viscosity & -1.013 & .685 & 2.183 & 1 & .140 & .363 & \\
Fiber & .677 & .566 & 1.433 & 1 & .231 & 1.968 & \\
Constant & .895 & .470 & 3.635 & 1 & .057 & 2.448 & \\
\hline
\end{tabular}

** Significant at $\mathrm{p}<0.05$

*Significant at $\mathrm{p}<0.1$

The taste and color of LRD are significant at $\mathrm{p}<0.05$ and $\mathrm{p}<0.01$ each. Therefore, taste and color represent the probability of respondents' purchase is 6.9 than of not being purchased $(p<0.1)$ with every unit increase in taste based on the odds ratio. Meanwhile, the color recorded probability of respondents' to purchase is 3.6 than of not being purchased $(p<0.05)$ with every unit increase in color. Both taste and color recorded the odd ratio greater that 1 which means there are higher probability to purchase for taste and moderate probability to purchase for the attribute color based in Table 2 . The other attributes are not significantly contribute to the respondents' purchase intention. The Nagelkerke $\mathrm{R}^{2}$ of 0.212 indicated that these variables accounted for $21.2 \%$ of the variance in the model. Therefore, these findings suggest that there are other factors that influenced the respondents to purchase and will be suggested for further research prior to the product launching.

\section{Conclusion}

The goal of this study was to assess the level of consumers' acceptance and purchase intentions towards LRD. The LRD is well accepted compared to the commercial beverages in the market. Color, taste, and viscosity are the top three highest for product attributes selected by respondents. For the purchase intention based on the product attributes, taste and color are the two significant attributes which lead to the higher probability of the consumers' to purchase. These indicator are important for the beverage manufacturers to promote the taste and color as the 'selling point' or strength of this product. Next, there was a significant relationship between the knowledge of functional food with the education level. Besides, there are also significant relationship ready to buy with the gender and overall consumers' acceptance. These demographic factors can considered by the beverages manufacturers to strategize their marketing strategy based on these findings. In a nutshell, this study provided valuable and beneficial output for the new functional beverage based on the local fruits for the beverage manufactures to exploit the opportunity in additional health benefits for the Malaysian beverage industry. 


\section{REFERENCES}

Chang, H.-P., Ma, C.-C., \& Chen, H.-S. (2020). The impacts of young consumers' health values on functional beverages purchase intentions. International journal of environmental research and public health, 17(10), 3479-3491.

Chua, Y. P. (2014). Ujian regresi, analisis faktor dan analisis SEM (2nd ed.). Shah Alam, Malaysia: McGraw-Hill Education.

Corbo, M. R., Bevilacqua, A., Petruzzi, L., Casanova, F. P., \& Sinigaglia, M. (2014). Functional beverages: the emerging side of functional foods: commercial trends, research, and health implications. Comprehensive reviews in food science and food safety, 13(6), 1192-1206.

Darusalam, G., \& Hussin, S. (2018). Research methodology in education (2nd ed.). Kuala Lumpur: University of Malaya.

Hardy, G. (2000). Nutraceuticals and functional foods: introduction and meaning. Nutrition (Burbank, Los Angeles County, Calif.), 16(7-8), 688-689.

Henry, C. J. (2010). Functional foods. European Journal of Clinical Nutrition, 64(7), 657-659.

Kwak, N.-S., \& Jukes, D. J. (2001). Functional foods. Part 1: the development of a regulatory concept. Food Control , 12(2), 99-107.

Luckow, T., \& Delahunty, C. (2004). Which juice is 'healthier'? A consumer study of probiotic non-dairy juice drinks. Food Quality and Preference , 15(7-8), 751-759.

Maoto, M. M., Beswa, D., \& Jideani, A. I. (2019). Watermelon as a potential fruit snack. International Journal of food properties, 22(1), 355-370.

Ministry of Agriculture and Food Industry . (2020). Crop Statistics Booklet (Food Crops Sub Sector). Retrieved 9 15, 2021, from

http://www.doa.gov.my/index.php/pages/view/622?mid=239

Mordor Intelligence. (2021). Functional Beverage Market - Growth, Trends, Covid-19 Impact, and Forecasts (2021-2026) . Retrieved 9 10, 2021, from

https://www.mordorintelligence.com/industry-reports/functional-beveragemarket?gclid=Cj0KCQjwh_eFBhDZARIsALHjIKcwk-ZSNCtIsOd6e4Tl_Id6mjLVF01zqmN4w_WPagty_Y1UeWEHJcaAgrmEALw_wcB

PF Guiné, R., Ramalhosa, E. C., \& Valente, L. P. (2016). New foods, new consumers: innovation in food product development. Current Nutrition \& Food Science, 12(3), 175189.

Piqueras-Fiszman, B., \& Spence, C. (2015). Sensory expectations based on product-extrinsic food cues: An interdisciplinary review of the empirical evidence and theoretical accounts. Food Quality and Preference, 40(Part A), 165-179.

Ried, K., \& Fakler, P. (2011). Protective effect of lycopene on serum cholesterol and blood pressure: Meta-analyses of intervention trials. Maturitas , 68(4), 299-310.

Sabbe, S., Verbeke, W., Deliza, R., Matta, V. M., \& Damme, P. V. (2009). Consumer liking of fruit juices with different açaí (Euterpe oleracea Mart.) concentrations. Journal offood science, 74(5), S171-S176.

Sahar, A., Rahman, U. u., Ishaq, A., Munir, M. S., \& Aadil, R. M. (2019). Health-Promoting Perspectives of Fruit-Based Functional Energy Beverages. Sports and Energy Drinks, 10(1), 399-439.

Siro, I., Kápolna, E., Kápolna, B., \& Lugasi, A. (2008). Functional food. Product development, marketing and consumer acceptance-A review. Appetite, 51(3), 456-467. 
Skąpska, S., Marszałek, K., Woźniak, Ł., Szczepańska, J., Danielczuk, J., \& Zawada, K. (2020). The Development and Consumer Acceptance of Functional Fruit-Herbal Beverages. Foods , 9(12), 1-16.

Stanton, C., Ross, R. P., Fitzgerald, G. F., \& Sinderen, D. V. (2005). Fermented functional foods based on probiotics and their biogenic metabolites. Current opinion in biotechnology, 16(2), 198-203.

Tschannen-Moran, M., \& Gareis, C. R. (2004). Principals' sense of efficacy: Assessing a promising construct. Journal of Educational administration, 42(5), 573-585.

Zaidel, Abang, D. N., Ida Idayu Muhamad, Z. H., Jusoh, Y. M., \& Salleh, E. (2021). Innovation and Challenges in the Development of Functional and Medicinal Beverages. In D. K. Mahapatra, C. N. Aguilar, \& A. K. Haghi (Eds.), Natural Products Pharmacology and Phytochemicals for Health Care (1st ed., pp. 157-217). New York: Natural Products Pharmacology and Phytochemicals for Health Care. 